\title{
The GNAS Complex Locus and Human Diseases Associated with Loss-of-Function Mutations or Epimutations within This Imprinted Gene
}

\author{
Serap Turan ${ }^{\mathrm{a}}$ Murat Bastepe ${ }^{\mathrm{b}}$ \\ a Pediatric Endocrinology, Marmara University School of Medicine Hospital, Istanbul, Turkey; ${ }^{b}$ Endocrine Unit, \\ Department of Medicine, Massachusetts General Hospital and Harvard Medical School, Boston, Mass., USA
}

\author{
Key Words \\ GNAS · Pseudohypoparathyroidism - a-Subunit of the \\ stimulatory $\mathrm{G}$ protein
}

\begin{abstract}
GNAS is a complex imprinted locus leading to several different gene products that show exclusive monoallelic expression. GNAS also encodes the a-subunit of the stimulatory $\mathrm{G}$ protein (Gsa), a ubiquitously expressed signaling protein that is essential for the actions of many hormones and other endogenous molecules. Gsa is expressed biallelically in most tissues but its expression is silenced from the paternal allele in a small number of tissues. The tissue-specific paternal silencing of Gsa results in different parent-of-origin-specific phenotypes in patients who carry inactivating GNAS mutations. In this paper, we review the GNAS complex locus and discuss how disruption of Gsa expression and the expression of other GNAS products shape the phenotypes of human disorders caused by mutations in this gene.
\end{abstract}

๑) 2013 S. Karger AG, Basel

The imprinted GNAS gene is located on the long arm of chromosome 20 in humans [1]. GNAS is a complex locus giving rise to multiple gene products, including transcripts that encode the $\alpha$-subunit of the stimulatory guanine nucleotide-binding protein (G protein) (Gs $\alpha$ ), extra- large Gsa (XLas), and neuroendocrine secretory protein 55 (NESP55), as well as the noncoding A/B (also referred to as $1 \mathrm{~A}$ ) and antisense transcripts (GNAS-AS1). Encoded by GNAS exons 1-13 is Gsa, which is a ubiquitously expressed signaling protein mediating the actions of many hormones and other endogenous molecules via the generation of intracellular cyclic AMP (cAMP) [2-4] (fig. 1). NESP55, XL $\alpha$ s, and $A / B$ (also referred to as $1 A$ or 1') all contain their own unique first exons, which are spliced onto exon 2 of GNAS, i.e. all of these transcripts from this point on are identical in their sequence to $G s \alpha$ [5-8]. GNAS-AS1 consists of distinct exons that do not overlap with any of the other exons $[9,10]$. There are also shortened neural transcripts of Gs $\alpha$ and XL $\alpha s$, termed Gs $\alpha$ N1 and XLN1, which terminate prematurely before exon 4 [11, 12] (fig. 1).

Genomic imprinting results in the expression of a subset of genes according to their parental origin. The GNAS cluster contains a number of differentially methylated regions (DMR) that encompass the promoters of the different transcripts. The promoters of $X L \alpha s, A / B$, and $A S$ transcripts are exclusively paternally expressed and the NESP55 transcript shows exclusive maternal expression, and their promoters are methylated on the inactive allele $[9,10,13-16]$ (fig. 1). The genomic region comprising the putative promoter of $G s \alpha$ is not methylated and, consistent with the absence of differential methylation in this region, the Gsa transcript is biallelically expressed in

\section{KARGER}

E-Mail karger@karger.com

www.karger.com/hrp (c) 2013 S. Karger AG, Basel

$1663-2818 / 13 / 0804-0229 \$ 38.00 / 0$
Serap Turan, MD

Pediatric Endocrinology and Diabetes, Marmara University Hospital Fevzi Cakmak Mh.Mimar Sinan Cd.No 41

Ustkaynarca/Pendik, TR-34899 Istanbul (Turkey) 


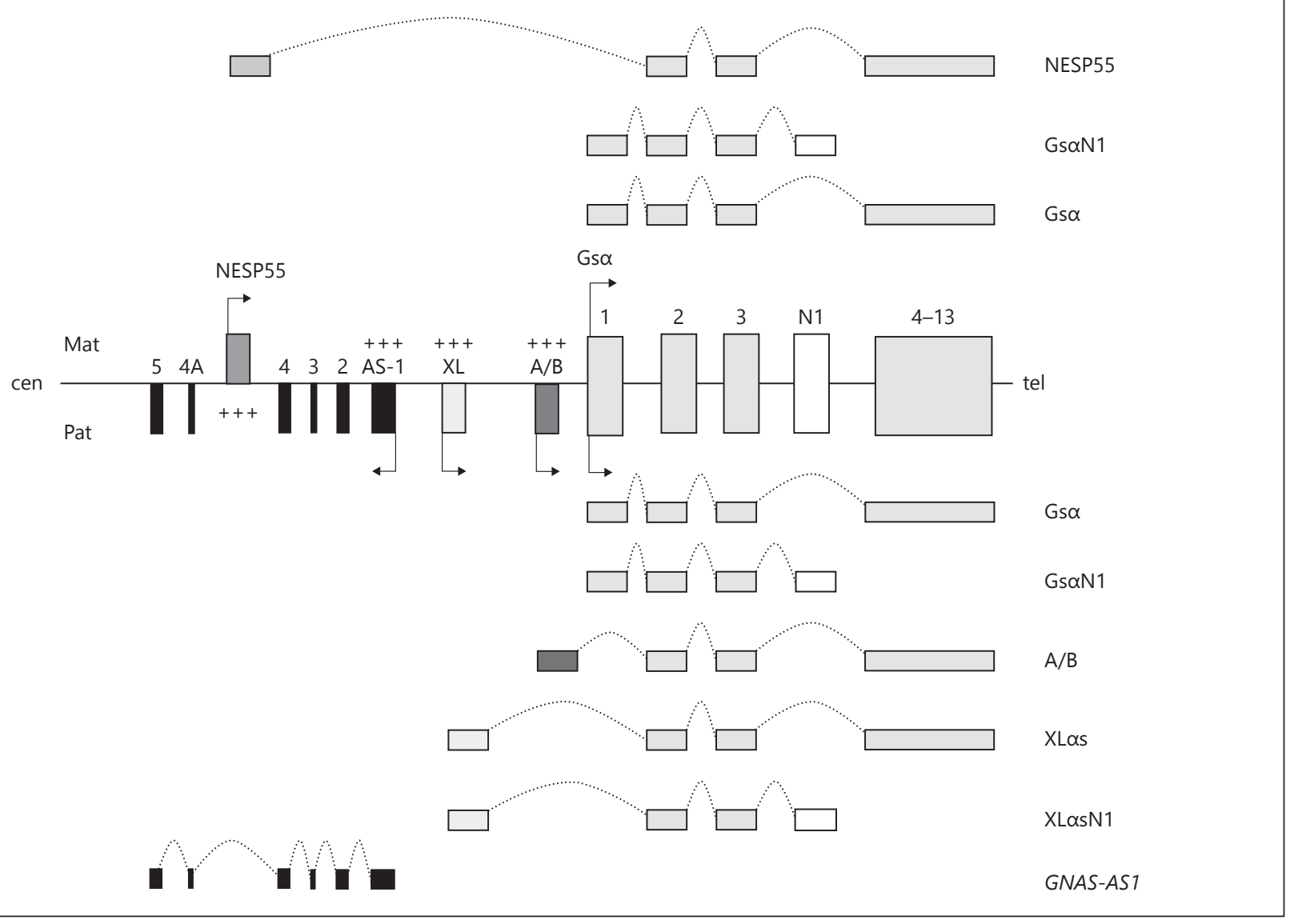

Fig. 1. Multiple imprinted sense and antisense transcripts from the complex GNAS locus. Exons 1-13 encode Gsa, which is biallelic in most tissues. Several other transcripts arise from differentially methylated promoters, including the maternally expressed NESP55 and the paternally expressed $X L \alpha s$ and $A / B$ (also referred to as $1 \mathrm{~A}$ or 1') and the neural transcript of Gsa and XL $\alpha s$ as GsaN1 and XLasN1, respectively. All of these transcripts use individual first exons that splice onto exons 2-13 of GNAS. Another noncoding transcript is also derived from the paternal GNAS allele by using

most tissues. However, as-yet-undefined mechanisms silence paternal Gsa expression in some tissues, including proximal renal tubules, neonatal brown adipose tissue, thyroid, gonads, the paraventricular nucleus of the hypothalamus and pituitary [17-23].

\section{Diseases Caused by Inactivating Mutations in Gsa-Coding GNAS Exons}

Genetic alterations affecting the GNAS complex locus are responsible for several inherited disorders. Consistent with the parent-of-origin-specific expression of Gsa in its own exons, but this transcript is made from the antisense strand (AS transcript, also referred to as Nespas in mice). Boxes and connecting lines depict exons and introns, respectively. Maternal (Mat) and paternal (Pat) GNAS products are illustrated above and below the gene structure, respectively, with splicing patterns indicated by broken lines. + indicate methylated DMR promoters either on the paternal allele (NESP55) or on the maternal allele ( $X L \alpha s, A / B, A S$ exon 1). Please note that the figure is not drawn to scale. some tissues, the phenotypes that are derived from these mutations depend on the parent transmitting the mutation. Pseudohypoparathyroidism (PHP) type I refers to partial or complete end-organ resistance to the actions of parathyroid hormone (PTH) and is characterized by a failure to increase urinary cAMP and urinary phosphate excretion in response to exogenous $\mathrm{PTH}$ administration $[2-4,24]$. In PHP-II, nephrogenous cAMP generation in response to exogenous PTH administration is normal, but the urinary excretion of phosphate is impaired [25]. Although the common biochemical features of PHP are hypocalcemia, hyperphosphatemia, and elevated PTH levels, Albright hereditary osteodystrophy (AHO) is a 
Table 1. Main disease subtypes related to impaired Gsa activity

\begin{tabular}{|c|c|c|c|c|c|c|c|}
\hline PHP-Ia & Yes & Yes & Yes & Blunted & Blunted & Reduced & $G s \alpha$ \\
\hline PHP-Ic & Yes & Yes & Yes & Blunted & Blunted & Normal $^{c}$ & $G s \alpha$ \\
\hline РPHP & No & No & Yes & Normal & Normal & Reduced & $G s \alpha$ \\
\hline $\mathrm{POH}^{\mathrm{a}}$ & No & No & No & Normal & Normal & Reduced & $G s \alpha$ \\
\hline PHP-Ib ${ }^{b}$ & Yes & No & No & Blunted & Blunted & Normal & $\begin{array}{l}\text { STX16 } \\
\text { NESP55/AS }\end{array}$ \\
\hline
\end{tabular}

\footnotetext{
${ }^{a} \mathrm{POH}$ patients sometimes have hormone resistance and/or mild AHO features; PTH-induced urinary excretion of cAMP and phosphate has been directly measured in few cases, but in most cases these are predicted to be normal because of the paternal origin of the mutations.

$\mathrm{b}$ The genetic defects alter the differential methylation status of GNAS. Some patients additionally show mild TSH resistance; in several cases AHO features have been reported. A recent study showed mildly diminished erythrocyte Gsa activity in a series of patients with GNAS methylation defects.

${ }^{c}$ In cases caused by Gsa mutations, a normal response is observed when stimulating the reconstituted erythrocytes with direct activators of $G s \alpha$.
}

part of the clinical picture in PHP-Ia, PHP-Ic, and occasionally PHP-Ib (table 1). The features of AHO, as described originally by Albright et al. [26], include obesity with a round face, short stature, brachydactyly, subcutaneous ossifications, and mental retardation (see below for details).

\section{PHP-Ia and PHP-Ic}

PHP-Ia is caused by heterozygous mutations located throughout the Gs $\alpha$-coding GNAS exons. Homozygous mutations that completely disrupt Gsa activity seem to be incompatible with life, as judged by embryonic lethality observed in mice with homozygous ablation of Gnas and by the absence of any homozygous mutations described in humans; however, a single case having a compound heterozygous mutation with $10-20 \%$ Gs $\alpha$ activity has been reported $[2,4,27]$.

Typically, the heterozygous mutations described in patients with PHP-Ia lead to impaired cAMP generation due to unstable or no Gsa protein from the mutant allele, or impaired stimulation of adenylyl cyclase by the mutant protein. This is evidenced in biochemical assays in which patient-derived erythrocytes are used to complement membranes from turkey erythrocytes or S49 murine lymphoma cell membranes that lack endogenous Gsa activity $[28,29]$. While these assays are utilized in the diagnosis of this disorder, a normal response in the presence of clinical features typical of PHP-Ia is the basis for the definition of PHP-Ic. Patients with PHP-Ic could carry mutations in other genes. However, Gs $\alpha$ mutants that are

GNAS and Pathophysiology able to stimulate adenylyl cyclase but are defective in receptor coupling also appear fully functional when the erythrocyte Gsa bioactivity assay is performed by using direct stimulators of Gsa activity, such as a GTP analog, rather than a receptor agonist. Several cases with PHP-Ic have been shown to carry these receptor-uncoupling $G s \alpha$ mutations, which are located near the C-terminal end of the Gsa molecule, consistent with the importance of this region in receptor interactions [2, 30, 31]. Nevertheless, the clinical phenotype of patients diagnosed with PHP-Ic is indistinguishable from that of patients diagnosed with PHP-Ia. By and large, genotype-phenotype correlation does not exist in diseases caused by inactivating GNAS mutations. However, a missense mutation (A366S) identified in 2 boys generates a temperature-sensitive $G s \alpha$ mutant that causes testotoxicosis due to constitutive activity at the lower temperature of the testes [32], but instability at body temperature, and an AVDT amino acid repeat insertion identified in 2 siblings, results in an unstable but overactive Gs $\alpha$ mutant that leads to transient neonatal diarrhea due to enhanced cAMP signaling in the gut [33].

Consistent with the fact that Gs $\alpha$ signaling and cAMP production play important roles in the action of a variety of hormones, PTH resistance is not the sole hormonal defect that results from inactivating Gs $\alpha$ mutations. Additional hormonal abnormalities including hypothyroidism, growth hormone deficiency, and hypogonadism are also demonstrable in patients with PHP-Ia, reflecting target-organ resistance to TSH, growth hor- 
mone-releasing hormone (GHRH), and gonadotropins [2-4].

Patients with PHP-Ia frequently present to the clinic with hypothyroidism due to end-organ resistance to TSH, which can sometimes be detected in neonatal screening for congenital hypothyroidism [2-4, 19-21, 34-36]. Although nearly all patients develop hypocalcemia, this defect often manifests itself later in life, usually after early childhood $[35,36]$. It is therefore possible that PTH resistance is delayed. Since the development of hormone resistance depends critically on the silencing of Gsa expression from the normal paternal allele, if there is latency in PTH resistance, this finding would suggest that the allelic Gsa silencing in the proximal renal tubule is established after the early postnatal period. Accordingly, no evidence for predominant maternal expression of Gsa has been found in human fetal renal cortex [37]. Using mice heterozygous for ablation of either maternal or paternal Gnas exon 1, we found that the biochemical features of PTH resistance develop after early postnatal development, and that expression of Gsa is biallelic in the mouse renal proximal tubule during early postnatal life but becomes maternal with age [unpubl. data]. It is currently unknown whether the predominantly maternal expression of Gsa is established earlier in life in other tissues. Future studies are required to address this question.

\section{PHP-Ia and Pseudopseudohypoparathyroidism}

Maternally inherited mutations in GNAS exons 1-13 lead to PHP-Ia with multiple hormone resistance and $\mathrm{AHO}$, whereas paternal inheritance of the same mutations leads to AHO features in the absence of hormone resistance. The latter condition is termed PPHP [38]. PHP-Ia and PPHP can be found in the same kindred, but not in the same sibship $[39,40]$. This parent-of-originspecific mode of inheritance for hormone resistance could be explained by the tissue-specific paternal silencing of Gsa. In the case of a maternal mutation, a significant loss of Gsa activity exists in those tissues in which paternal Gsa is silenced, thus leading to hormone resistance. When inherited paternally, the same mutations do not severely reduce the Gsa activity and allow normal hormone responsiveness. On the other hand, heterozygous inactivating mutations of Gs $\alpha$ lead to $50 \%$ loss of protein activity in tissues in which Gsa expression is biallelic, such as skin fibroblasts, erythrocytes, white adipose tissue, bone, and growth plate chondrocytes [17, 28, 29, 34, 41, 42]. Clinical findings related to those tissues are due presumably to $G s \alpha$ haploinsufficiency and are found independently of the parental origin of the mutation. The actions of some hormones, such as antidiuretic hormone and $\mathrm{ACTH}$, seem to be unimpaired despite the $50 \%$ reduction in Gsa activity in their target tissues [34, 43, 44], indicating a lack of haploinsufficiency.

AHO features, which are fairly nonspecific, can be present in a patient regardless of the parental origin of the Gs $\alpha$ mutation. Thus, it is thought that AHO results primarily from Gsa haploinsufficiency in those tissues where Gsa expression is biallelic. Consistent with this interpretation, growth plate chondrocytes that lack either the maternal or the paternal Gsa allele differentiate into hypertrophic chondrocytes earlier than wild-type chondrocytes in a chimeric mouse model [42]. Likewise, mice with ablation of Gnas exon 1 develop subcutaneous ossifications regardless of whether the disrupted allele is inherited from the mother or the father [45]. Nonetheless, recent data from human studies have revealed that obesity and cognitive impairment occur predominantly in patients with PHP-Ia rather than PPHP [46, 47], indicating that the mechanisms leading to these AHO features involve Gsa imprinting.

\section{Progressive Osseous Heteroplasia}

Progressive osseous heteroplasia $(\mathrm{POH})$ is a severe, rare manifestation of AHO characterized by severe heterotopic ossification that affects deep connective tissue and skeletal muscle [48]. Patients with $\mathrm{POH}$ often lack any features of $\mathrm{AHO}$ or hormone resistance. Based on published cases, it appears that the great majority of GNAS mutations leading to $\mathrm{POH}$ are inherited paternally [49-51], suggesting the involvement of a loss or impaired function of the paternally expressed protein in the development of the severe ossifications. GNAS mutations identified in patients with $\mathrm{POH}$ are the same as those found in PHP-Ia or PPHP, and it is unclear why some cases present only with PHP-Ia or PPHP while others develop $\mathrm{POH}[3,48-51]$. This phenotypic variation and different disease presentation of a GNAS mutation might involve the genetic background, epigenetic changes, and/ or environmental factors.

\section{Mouse Models of PHP-la}

The homozygous disruption of Gnas exon 1, which is exclusively utilized by Gsa, causes embryonic lethality during early postimplantation stages, consistent with the essential roles of this protein in numerous cellular functions $[52,53]$. Heterozygous disruption of this exon on the maternal allele (Gnas $\mathrm{E} 1 \mathrm{~m}-/ \mathrm{p}+$ ) leads to moderate 
Table 2. Phenotypes of Gnas disruption in mice that resemble human diseases caused by GNAS mutations

\begin{tabular}{|c|c|c|c|c|}
\hline & $\begin{array}{l}\text { Deleted } \\
\text { allele }\end{array}$ & Affected proteins & Phenotype & References \\
\hline \multirow[t]{2}{*}{$\begin{array}{l}\text { Gnas } \\
\text { exon } 1\end{array}$} & Paternal & Paternal Gsa & $\begin{array}{l}\text { Mildly decreased body weight and length, } \\
\text { heterotopic ossification }\end{array}$ & $45,52,53,54$ \\
\hline & Maternal & Maternal Gsa & $\begin{array}{l}\text { Perinatal mortality, and neonatal edema } \\
\text { Adults: PTH resistance, increased adiposity with } \\
\text { normal food intake, decreased length, a low } \\
\text { metabolic rate, decreased sympathetic activity, } \\
\text { and heterotopic ossification }\end{array}$ & $45,52,53,54$ \\
\hline \multirow[t]{2}{*}{$\begin{array}{l}\text { Gnas } \\
\text { exon } 2\end{array}$} & Paternal & Paternal Gsa, XLas, XLN1 & $\begin{array}{l}\text { Perinatal mortality, poor suckling, decreased } \\
\text { adiposity } \\
\text { Adults: lean phenotype with decreased adiposity, } \\
\text { a high metabolic rate, decreased length, increased } \\
\text { sympathetic nervous system activity, and } \\
\text { fibromatous skin tumors }\end{array}$ & $17,53,55,62$ \\
\hline & Maternal & Maternal Gsa & $\begin{array}{l}\text { Neonatal edema and preweaning mortality } \\
\text { Adults: PTH resistance, increased adiposity with } \\
\text { normal food intake, decreased length, a low } \\
\text { metabolic rate, decreased sympathetic activity, } \\
\text { and fibromatous skin tumors }\end{array}$ & $17,53,55,62$ \\
\hline Gnasxl & Paternal & XLas, XLN1, ALEX ${ }^{a}$ & $\begin{array}{l}\text { Perinatal mortality, poor suckling, decreased } \\
\text { adiposity } \\
\text { Adults: lean phenotype with decreased adiposity, } \\
\text { a high metabolic rate, decreased length, and } \\
\text { increased sympathetic activity }\end{array}$ & 56,57 \\
\hline \multirow[t]{2}{*}{$\begin{array}{l}\text { ENU point } \\
\text { mutation } \\
\text { Gnas } \\
\text { exon } 6\end{array}$} & $\begin{array}{l}\text { Paternal } \\
(\mathrm{Sml})\end{array}$ & Paternal Gsa, XLas & $\begin{array}{l}\text { Preweaning lethality, postnatal growth retardation } \\
\text { with normal suckling, small body size } \\
\text { Adults: an increased metabolic rate, small body } \\
\text { size, decreased length and BMI, adiposity } \\
\text { unaffected by a high-fat diet, mild PTH elevation, } \\
\text { hypocalcemia, hypophosphatemia, and } \\
\text { heterotopic ossification }\end{array}$ & $58-61$ \\
\hline & $\begin{array}{l}\text { Maternal } \\
\text { (Oed) }\end{array}$ & Maternal Gsa & $\begin{array}{l}\text { Perinatal mortality and edema, microcardia } \\
\text { Adults: PTH resistance, increased adiposity, low } \\
\text { metabolic rate, heterotopic ossification }\end{array}$ & $58-61$ \\
\hline Nesp55 DMR ${ }^{\mathrm{b}}$ & Maternal & $\begin{array}{l}\text { Nesp55 } \\
\text { Maternally silenced Gsa in some tissues } \\
\text { Maternally derepressed 1A, XLas }\end{array}$ & $\begin{array}{l}\text { Neonatal edema; hypoglycemia; } 100 \% \text { early } \\
\text { postnatal mortality } \\
\text { PTH resistance }\end{array}$ & 83,84 \\
\hline
\end{tabular}

\footnotetext{
a ALEX is an alternative protein of unknown function, generated from the XLas exon alone through the use of an alternative reading frame.

b Paternal deletion of the Nesp55 DMR has no detectable phenotype.
}

(50\%) preweaning mortality and edema at birth $[52,53]$. Surviving mice show a phenotype similar to that observed in PHP-Ia patients, including obesity, a decreased metabolic rate, and PTH resistance [52, 54] (table 2). Evidence for TSH resistance was not observed in one of the mouse models in which Gnas exon 1 was ablated [53], while el- evated TSH was documented in another model [52]. This discrepancy likely reflects strain-specific differences, although it is conceivable that it results from the difference in the extent of the genomic deletion between these two models. Interestingly, mildly elevated PTH and TSH levels have been reported for one of the two knockout mod- 
els when the disruption is inherited paternally [52]. Likewise, in the other paternal Gnas exon 1 knockout mouse model, our recent analyses demonstrated a mild elevation of PTH at 3 weeks of age [unpubl. data]. Unlike these findings in mice with paternal disruption of Gnas, humans with paternal heterozygous inactivating mutations of GNAS, i.e. patients with PPHP, have not been reported to have any evidence for hormone resistance.

Disruption of maternal Gnas exon 2 results in a phenotype fairly similar to that caused by disruption of maternal Gnas exon $1[17,55]$ (table 2). However, the same is not true for disruption of paternal Gnas exon 2 (Gnas $\mathrm{E} 2 \mathrm{~m}+/ \mathrm{p}-)$, as this genetic modification leads to severe early postnatal lethality and defects in glucose and energy metabolism. A small percentage of Gnas E2m+/p- mice survive to adulthood and show apparently normal life spans when crossed to outbred strains, but those mice are hypermetabolic and lean [55]. The phenotype of Gnas $\mathrm{E} 2 \mathrm{~m}+/ \mathrm{p}$ - mice is strikingly similar to the phenotype of mice in which XL $\alpha$ s is ablated (Gnasxl $\mathrm{m}+/ \mathrm{p}-$ mice) (table 2), implicating the deficiency of this paternally expressed Gnas product in the phenotype [56, 57].

The oedematous-small (Oed-Sml) is another mouse model of the Gnas locus in which a point mutation in Gnas exon 6 (V159E) is induced by ethylnitrosourea (ENU) $[58,59]$ (table 2). Maternally transmitted mutations result in microcardia with gross edema $(\mathrm{Oed})$; note that neonatal edema has been reported for mice with maternal heterozygous Gnas exon 1 ablation [52, 53]. However, when this point mutation is transmitted paternally, the offspring shows growth retardation $(\mathrm{Sml})$, which is likely related to the disruption of the paternally expressed Gnas product XLas [58-60]. Both of these maternal and paternal phenotypes are early postnatal and are associated with high lethality within this developmental period [59]. In surviving adult mice carrying this point mutation on the maternal allele, hypocalcemia, hyperphosphatemia, and elevated PTH levels have been documented, consistent with the findings observed in PHP-Ia patients [18]. Recent investigations have also revealed mildly elevated PTH and hypocalcemia in older (>12 months) Sml mice, but these biochemical changes have been accompanied by hypophosphatemia, unlike the findings in Oed mice and other mouse models with maternal Gsa ablation, which show hyperphosphatemia [61].

Subcutaneous heterotopic ossifications, as seen in patients with $\mathrm{AHO}$, have also been documented in mice heterozygous for Gnas exon 1 ablation and in Oed/Sml mice $[45,61]$ (table 2 ). By 1 year of age, nearly all male mice with these genetic modifications develop subcutaneous ossifications, but precursor lesions can be detected by histological analyses as early as 3 months of age [45]. Similar to the findings in patients with $\mathrm{AHO}$, the ossifications develop regardless of the parent of origin, implicating the deficiency of biallically expressed Gsa in the pathogenesis. In mice heterozygous for Gnas exon 2 disruption, osseous lesions have not been detected, but instead calcified fibromas or angiofibromas of the skin are found by 4 months of age, independently of whether the maternal or the paternal Gnas exon 2 is disrupted [62] (table 2).

\section{PHP Type Ib: Hormone Resistance Caused by Epigenetic Alterations of GNAS}

In certain patients, hormone resistance is confined to the renal proximal tubular action of $\mathrm{PTH}$, and this form of PHP is defined as PHP type Ib [2-4]. Some PHP-Ib patients have been shown to have mildly elevated TSH levels, indicating TSH resistance [21]. Some recent studies have also shown that AHO features can exist in patients who have epigenetic abnormalities of GNAS that are typically found in PHP-Ib [63-66].

\section{Autosomal Dominant PHP-Ib}

Most PHP-Ib cases are sporadic, but some cases are familial and inherited in an autosomal dominant fashion (AD-PHP-Ib). Similar to the hormone resistance in PHP$\mathrm{Ia}$, the hormone resistance in PHP-Ib is inherited only from female obligate carriers $[67,68]$, yet no mutations in GNAS exons encoding Gsa have been described in patients with PHP-Ib. On the other hand, a genetic linkage analysis has mapped AD-PHP-Ib to a locus within the telomeric end of chromosome $20 \mathrm{q}$ which comprises the GNAS locus [67]. It has subsequently been revealed that PHP-Ib patients have methylation defects within GNAS $[68,69]$ and, accordingly, various paternal uniparental disomies involving chromosome 20 have been documented in some PHP-Ib patients who lack the maternal methylation pattern in this locus [70-74]. The most consistent epigenetic abnormality in both sporadic and familial PHP-Ib is a loss of methylation in the exon A/B DMR, which is often the only methylation defect in AD-PHP-Ib cases (fig. 2) [68, 69].

In patients with $\mathrm{AD}-\mathrm{PHP}-\mathrm{Ib}$, genetic studies have revealed deletions in the neighboring STX16 locus, the gene encoding syntaxin $16[75,76]$. Recently, a large deletion removing GNAS exon NESP55 was discovered in a single AD-PHP-Ib family [77]. Both the STX16 and the NESP55 deletions are inherited from female obligate carriers, con- 


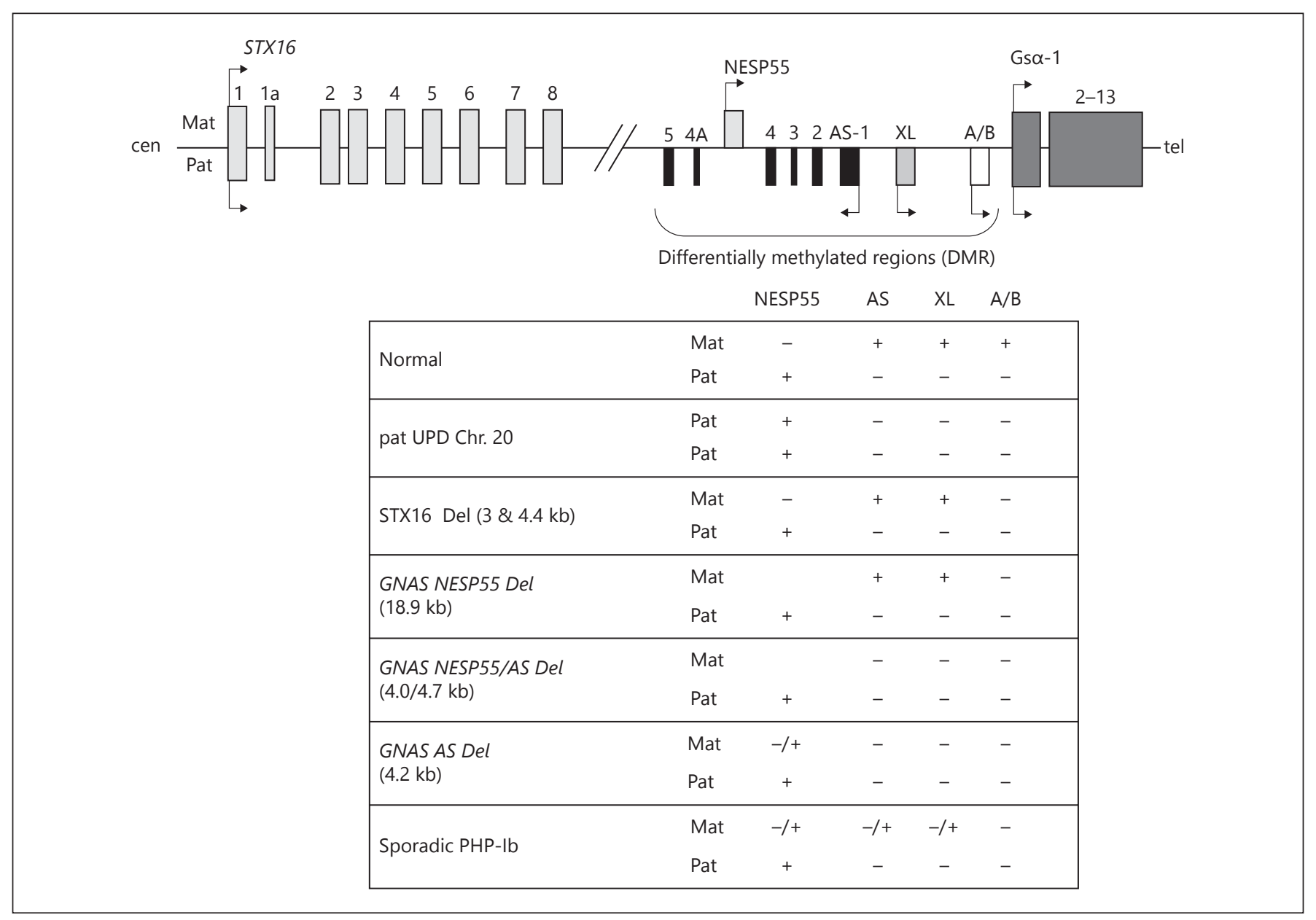

Fig. 2. Genetic and epigenetic defects causing PHP-Ib. Maternal $S T X 16$ deletions cause isolated $A / B$ loss of methylation; maternal deletion of NESP55 leads to isolated $A / B$ loss of methylation with hemizygosity in NESP55. However, maternal deletions affecting $A S$ exons 3 and 4 result in a loss of methylation at all maternal
GNAS imprints. Sporadic PHP-Ib cases show loss of methylation at exon $X L$, the promoter of $A S$, and exon $A / B$, and a gain of methylation at NESP55. Please note that the figure is not drawn to scale. Note that the methylation changes at the NESP55, AS promoter, and XL in sporadic PHP-Ib cases are often, but not always, partial.

Some AD-PHP-Ib cases show methylation defects in multiple GNAS DMR. In 3 unrelated AD-PHP-Ib families in whom affected individuals showed methylation defects in all GNAS DMR, deletions of all or part of the NESP55 DMR have been identified, including exon NESP55 and exons 3 and 4 of the GNAS-AS1 transcript $[81,82]$. In 2 families, the deletions are nearly identical and remove the entire NESP55 DMR [81]. In the third family, the sequences comprising exon NESP55 are preserved, but GNAS-AS1 transcript exons 3 and 4 are deleted along with a significant portion of intron 2 [82]. The deletions affecting the NESP55 DMR also point to a cisacting element regulating the imprinting of the maternal GNAS allele. In fact, maternal deletion of the entire 
Nesp55 DMR in mice leads to loss of all maternal Gnas methylation imprints, leading in kidneys to increased $1 \mathrm{~A}$ transcription and decreased Gs $\alpha$ mRNA levels, and to hypocalcemia, hyperphosphatemia, and hyperparathyroidism; note that no methylation abnormality has been detected in mice that inherited this deletion paternally [83, 84] (table 2). Furthermore, the maternal Nesp55 deletion in mice leads to hypoglycemia and $100 \%$ mortality during the early postnatal period $[83,84]$. Recent investigations have revealed that the loss of XL $\alpha$ s imprinting, which is associated with a two-fold increase in the expression of this Gnas transcript, is responsible for the early postnatal hypoglycemia and lethality in mice with maternal deletion of Nesp55 DMR [84]. Normalization of the XLas expression level in the latter mice by crossing them with mice in which the paternal XL $\alpha$ s allele is disrupted allows generation of double-mutant offspring that show markedly improved survival, thus providing a viable model of human AD-PHP-Ib [84] (table 2). It should be noted that the early postnatal lethality and hypoglycemia phenotypes in the latter mice are not typical features of patients with PHP-Ib, although neonatal hypoglycemia has been described in a single patient with paternal UPD of chromosome $20 \mathrm{q}$ who had PHP-Ib and broad GNAS imprinting defects including a loss of XL $\alpha$ s imprinting [70]. The phenotypic consequence of XL $\alpha$ s loss of imprinting may be specific to mice or it may be compensated or masked by other genetic or environmental factors in humans.

\section{Sporadic PHP-Ib}

Epigenetic changes that involve multiple GNAS DMR are mostly observed in sporadic PHP-Ib patients [85]. As indicated above, some of these patients carry paternal uniparental disomy involving a part or the whole of chromosome $20 \mathrm{q}$, but the genetic cause of these methylation abnormalities in most sporadic cases remains to be identified $[70-74,86]$. De novo single or multiple base pair changes in the region spanning NESP55/AS exons 3 and 4 are plausible or, as suggested previously [85], these methylation changes could occur stochastically. Additionally, it is possible that the epigenetic abnormalities in sporadic cases, which tend to be incomplete, result from genetic defects in a trans-acting factor necessary for the maintenance of methylation at GNAS and, perhaps, some other imprinted loci. In fact, methylation defects in GNAS have been identified in combination with methylation defects in other loci in the context of certain other disorders $[87,88]$. In addition, a recent study of sporadic PHP-Ib cases revealed methylation changes in the DLK1/GTL2 or the PEG1/MEST locus [89]. The clinical significance of the loss of methylation at DLK1/GTL2, detected in one sporadic PHP-Ib case, could not be examined. On the other hand, the loss of methylation at PEG1/MEST, found in another sporadic PHP-Ib case, could perhaps explain the finding that this case had the highest BMI within the study population [89], given that the loss of the paternally expressed PEG1/MEST gene causes embryonic growth retardation, and a loss of maternal methylation marks at this locus may therefore result in the biallelic expression of PEG1/MEST and fetal overgrowth [90].

\section{Potential Roles of Other GNAS Transcripts in Physiology and Disease}

As shown in figure 1, multiple transcripts originate from the GNAS locus, but unlike Gs $\alpha$ these GNAS products have remained largely obscure in terms of their specific cellular roles.

\section{XLas Transcript}

XLas shares a significant portion of its amino acid sequence with Gsa, whereas the other GNAS products that utilize exons 2-13 do not have this portion as part of the primary protein structure (see below for details and possible exceptions). Therefore, $X L \alpha s$ appears to be an important Gs $\alpha$ variant that may have roles that are similar to the roles of the latter. While Gsa is expressed ubiquitously, XLas displays a more discrete expression pattern; it is expressed primarily in neuroendocrine tissues, such as the pituitary and orexigenic neurons in the hypothalamus of neonatal and adult rodents $[5,12,14$, 56, 91-93]. Its expression has been detected in a number of other tissues and cells in humans and rodents, including pancreas, white and brown adipose tissue, platelets, kidney, and various types of muscle cells $[5,12,14,56$, 93]. Studies have shown that XLas can function as a distinct $\alpha$-subunit of the heterotrimeric Gs signaling protein $[54,94-96]$. In fact, XLas remains more stably on the plasma membrane than Gsa and, at least under certain conditions, is able to produce receptor-stimulated cAMP formation more potently and in a more prolonged manner than Gsa [97]. Recently, hypermethylation of the XL $\alpha s$ DMR, along with reduced XLas protein expression in platelets, was reported in certain patients who had Gs hypofunction in their platelets and an AHO-like phenotype in the absence of coding Gs $\alpha$ mutations [98], thus supporting a Gsa-like role for XLas. The phenotype of Gnasxl m+/p- mice is vastly different 
from, and in many ways the opposite of, the phenotype of mice in which Gsa (but not XLas) is ablated; note that the latter mice are heterozygous for ablation of Gsa exon $1[52,53]$. On the other hand, the study of Gnasxl m+/pmice has clearly revealed that XLas is essential for early postnatal adaptation to feeding and survival, as well as glucose counterregulation [56, 57]. Consistent with these findings, which were shown in some but not all of the other mouse models in which the XLas transcript was ablated, some pediatric patients with perinatal developmental defects and intractable feeding difficulties have been reported to have large paternal deletions of GNAS [99, 100]. Furthermore, recent studies of patients with POH or PPHP have indicated that paternal GNAS mutations are associated with a low birth weight [101, $102]$. Based on evidence from different mouse models, however, it remains plausible that some of the early postnatal phenotypes, such as poor suckling, observed in Gnasxl $\mathrm{m}+/ \mathrm{p}-$ mice and in patients with large paternal GNAS deletions reflect the ablation of other gene products that use exon XL but not XLas itself $[56,57,59,103]$. Recent analyses in mice have also implicated XLas functions in bone and mineral metabolism. As explained above, older ( $>12$ months old) $\mathrm{Sml}$ mice were shown to have mild hypocalcemia, hypophosphatemia, and elevated serum PTH [61]. Moreover, mild hypocalcemia and marked hyperphosphatemia was documented in 10day old Gnasxlm+/p- pups [84]. In addition, bone mineral density was found to be diminished in a mouse model in which both XLas and XLas-N1 was ablated together with loss of Gsa imprinting [103].

\section{A/B Transcript}

The A/B transcript is biallelically expressed in patients with PHP-Ib due to a loss of methylation in its promoter [68-70]. It is thought that, under normal conditions, a trans-acting protein expressed in certain tissues, such as renal proximal tubules, binds to the unmethylated region at the exon $A / B$ DMR and thereby silences - either directly or by blocking the effect of an enhancer element the promoter of $G s \alpha$, which is about $2 \mathrm{~kb}$ downstream [15, $18,104]$. While this is a plausible hypothesis, another possibility is that the activity of the $A / B$ promoter results in transcriptional interference on the downstream $G s \alpha$ promoter in a tissue-specific manner. Studies with various genetically manipulated mice have shown that the exon $A / B$ (referred to as $1 \mathrm{~A}$ in mice) DMR on the paternal allele is required for the tissue-specific paternal silencing of $G s \alpha[18,104]$. In addition, evidence supporting a negative effect of A/B transcription on the Gs $\alpha$ promoter has been obtained by generating mice in which the A/B transcript was prematurely truncated [103]. Furthermore, the $A / B$ transcript can code for a truncated Gsa-like protein by using an initiation codon in exon 2 [7]. Evidence for the existence of this protein could be obtained by analyzing fetal kidney lysates [105]. In transfected cells, overexpression of this A/B protein inhibited $\mathrm{PTH}$-mediated and, less potently, TSH-mediated cAMP production, raising the possibility that the hormone resistance phenotype in PHP-Ib patients is due, at least partly, to the biallelic (i.e. doubled) expression of the A/B protein [105].

\section{NESP55 Transcript}

NESP55 is a chromogranin-like neurosecretory protein. Its expression is often lost in patients with $\mathrm{PHP}-\mathrm{Ib}$ due to a gain of methylation at its promoter $[69,70]$. No phenotype, however, can be attributed to the loss of NESP55 expression in those patients, whose clinical findings seem to be apparently identical to the clinical findings of those who have normal NESP55 methylation [69, 106]. Ablation of the Nesp 55 protein in mice is not associated with an early postnatal or developmental phenotype, but in adult mice it results in a mild behavioral phenotype that involves abnormal reactivity to novel environments [107]. On the other hand, an oocyte-specific Nesp55 transcript has been identified in mice, and premature termination of Nesp55 transcription through introduction of a polyadenylation cassette into the Gnas locus leads to a loss of methylation at exon $A / B$ and, in some cases, at other Gnas DMR [108]. Thus, at least one of the important roles of NESP55 appears to be in the regulation of imprinting at this complex locus, and it appears likely that the maternal deletions of the NESP55 DMR in PHPIb patients result in a loss of GNAS methylation because they disrupt NESP55 transcription.

\section{GNAS-AS1 Transcript}

The GNAS-AS1 transcript (referred to as Nespas in mice) is a noncoding paternally expressed transcript $[9$, 10]. Studies in mice have shown that it is required for silencing Nesp55 expression on the paternal allele [109, 110]. Accordingly, one of the deletions identified in an AD-PHP-Ib kindred results in the reduction of GNAS$A S 1$ expression in unaffected carriers, who inherit this deletion paternally [82], and these individuals show a partial loss of NESP55 methylation, indicating derepression of NESP55 transcription [82]. Also present in these unaffected carriers is a partial gain of methylation at exon $A / B$ DMR [82], consistent with a role of NESP 55 transcription in regulating methylation of downstream GNAS DMR, as 
explained above [108]. However, since the deletion identified in these unaffected carriers is located on the paternal allele [82], the latter finding suggests that NESP55 transcription may perhaps regulate GNAS DMR not only in the female germ line but also in the male germ line or somatic tissues.

In summary, the imprinted GNAS complex locus, which gives rise to the ubiquitously expressed signaling protein Gsa and other imprinted gene products, is critical for the actions of many hormones, and genetic defects in this gene lead to PHP and related diseases. Although these human disorders have been explored for decades, further genetic studies, together with generation and investigations of mouse models, are required to improve their understanding at the genetic, molecular, and clinical levels.

\section{Acknowledgments}

The studies conducted in the laboratory of M.B. were funded in part by research grants from the National Institute of Diabetes and Digestive and Kidney Diseases, the March of Dimes Foundation, and the Milton Fund. S.T. was supported by a Sabbatical Leave Programme grant from the European Society for Paediatric Endocrinology through an educational grant from Lilly USA, LLC.

\section{References}

1 Blatt C, Eversole-Cire P, Cohn VH, Zollman S, Fournier RE, Mohandas LT, Nesbitt M, Lugo T, Jones DT, Reed RR, Weiner LP, Sparkes RS, Simon MI: Chromosomal localization of genes encoding guanine nucleotide-binding protein subunits in mouse and human. Proc Natl Acad Sci USA 1988;85: 7642-7646.

2 Levine MA: Pseudohypoparathyroidism; in Bilezikian JP, Raisz LG, Rodan GA (eds): Principles of Bone Biology. New York, Academic Press, 2002, pp 1137-1163.

3 Weinstein LS, Yu S, Warner DR, Liu J: Endocrine manifestations of stimulatory $\mathrm{G}$ protein alpha-subunit mutations and the role of genomic imprinting. Endocr Rev 2001;22:675705.

4 Bastepe M, Jüppner H: Pseudohypoparathyroidism: new insights into an old disease. Endocrinol Metab Clin North Am 2000;29:569589.

5 Kehlenbach RH, Matthey J, Huttner WB: XL alpha $s$ is a new type of $G$ protein. Nature 1994;372:804-809.

6 Ischia R, Lovisetti-Scamihorn P, Hogue-Angeletti R, Wolkersdorfer M, Winkler H, Fischer-Colbrie R: Molecular cloning and characterization of NESP55, a novel chromograninlike precursor of a peptide with 5-HT1B receptor antagonist activity. J Biol Chem 1997;272:11657-11662.

7 Ishikawa Y, Bianchi C, Nadal-Ginard B, Homcy CJ: Alternative promoter and 5' exon generate a novel $\mathrm{G}_{\mathrm{s}} \alpha$ mRNA. J Biol Chem 1990;265:8458-8462.

-8 Swaroop A, Agarwal N, Gruen JR, Bick D, Weissman SM: Differential expression of novel Gs alpha signal transduction protein cDNA species. Nucleic Acids Res 1991;19: 4725-4729.

-9 Hayward B, Bonthron D: An imprinted antisense transcript at the human GNAS1 locus. Hum Mol Genet 2000;9:835-841.

10 Wroe SF, Kelsey G, Skinner JA, Bodle D, Ball ST, Beechey CV, Peters J, Williamson CM: An imprinted transcript, antisense to Nesp, adds complexity to the cluster of imprinted genes at the mouse Gnas locus. Proc Natl Acad Sci USA 2000;97:3342-3346.

-11 Crawford JA, Mutchler KJ, Sullivan BE, Lanigan TM, Clark MS, Russo AF: Neural expression of a novel alternatively spliced and polyadenylated Gs alpha transcript. J Biol Chem 1993;268:9879-9885.

12 Pasolli HA, Klemke M, Kehlenbach RH, Wang Y, Huttner WB: Characterization of the extra-large $G$ protein alpha-subunit XLalphas. 1. Tissue distribution and subcellular localization. J Biol Chem 2000;275:3362233632.

13 Hayward BE, Kamiya M, Strain L, Moran V, Campbell R, Hayashizaki Y, Bonthron DT: The human GNAS1 gene is imprinted and encodes distinct paternally and biallelically expressed G proteins. Proc Natl Acad Sci USA 1998;95:10038-10043.

14 Hayward BE, Moran V, Strain L, Bonthron DT: Bidirectional imprinting of a single gene: GNAS1 encodes maternally, paternally, and biallelically derived proteins. Proc Natl Acad Sci USA 1998;95:15475-15480.

15 Liu J, Yu S, Litman D, Chen W, Weinstein L: Identification of a methylation imprint mark within the mouse Gnas locus. Mol Cell Biol 2000;20:5808-5817.

16 Peters J, Wroe SF, Wells CA, Miller HJ, Bodle D, Beechey CV, Williamson CM, Kelsey G: A cluster of oppositely imprinted transcripts at the Gnas locus in the distal imprinting region of mouse chromosome 2. Proc Natl Acad Sci USA 1999;96:3830-3835.

17 Yu S, Yu D, Lee E, Eckhaus M, Lee R, Corria Z, Accili D, Westphal H, Weinstein LS: Variable and tissue-specific hormone resistance in heterotrimeric Gs protein alpha-subunit (Gsalpha) knockout mice is due to tissue-specific imprinting of the Gsalpha gene. Proc Natl Acad Sci USA 1998;95:8715-8720.

18 Williamson CM, Ball ST, Nottingham WT, Skinner JA, Plagge A, Turner MD, Powles N,
Hough T, Papworth D, Fraser WD, Maconochie M, Peters J: A cis-acting control region is required exclusively for the tissue-specific imprinting of Gnas. Nat Genet 2004;36:894899.

19 Mantovani G, Ballare E, Giammona E, BeckPeccoz P, Spada A: The Gsalpha gene: predominant maternal origin of transcription in human thyroid gland and gonads. J Clin Endocrinol Metab 2002;87:4736-4740.

20 Germain-Lee EL, Ding CL, Deng Z, Crane JL, Saji M, Ringel MD, Levine MA: Paternal imprinting of Galpha(s) in the human thyroid as the basis of TSH resistance in pseudohypoparathyroidism type 1a. Biochem Biophys Res Commun 2002;296:67-72.

21 Liu J, Erlichman B, Weinstein LS: The stimulatory $\mathrm{G}$ protein alpha-subunit Gs alpha is imprinted in human thyroid glands: implications for thyroid function in pseudohypoparathyroidism types $1 \mathrm{~A}$ and $1 \mathrm{~B}$. J Clin Endocrinol Metabol 2003;88:4336-4341.

22 Chen M, Wang J, Dickerson KE, Kelleher J, Xie T, Gupta D, Lai EW, Pacak K, Gavrilova $\mathrm{O}$, Weinstein LS: Central nervous system imprinting of the $\mathrm{G}$ protein $\mathrm{G}(\mathrm{s})$ alpha and its role in metabolic regulation. Cell Metab 2009; 9:548-555.

23 Hayward B, Barlier A, Korbonits M, Grossman A, Jacquet P, Enjalbert A, Bonthron D: Imprinting of the G(s)alpha gene GNAS1 in the pathogenesis of acromegaly. J Clin Invest 2001;107:R31-R36.

24 Chase LR, Melson GL, Aurbach GD: Pseudohypoparathyroidism: defective excretion of $3^{\prime}, 5^{\prime}$-AMP in response to parathyroid hormone. J Clin Invest 1969;48:1832-1844.

25 Drezner M, Neelon FA, Lebovitz HE: Pseudohypoparathyroidism type II: a possible defect in the reception of the cyclic AMP signal. $\mathrm{N}$ Engl J Med 1973;289:1056-1060.

26 Albright F, Burnett CH, Smith PH, Parson W: Pseudohypoparathyroidism: an example of 'Seabright-Bantam syndrome'. Endocrinology 1942;30:922-932. 
-27 Freson K, Izzi B, Jaeken J, Van Helvoirt M, Thys C, Wittevrongel C, de Zegher F, Van Geet C: Compound heterozygous mutations in the GNAS gene of a boy with morbid obesity, thyroid-stimulating hormone resistance, pseudohypoparathyroidism, and a prothrombotic state. J Clin Endocrinol Metab 2008;93: 4844-4849.

28 Farfel Z, Brickman AS, Kaslow HR, Brothers VM, Bourne HR: Defect of receptor-cyclase coupling protein in pseudohypoparathyroidism. N Engl J Med 1980;303:237-242.

29 Levine MA, Eil C, Downs RW Jr, Spiegel AM: Deficient guanine nucleotide regulatory unit activity in cultured fibroblast membranes from patients with pseudohypoparathyroidism type I: a cause of impaired synthesis of $3^{\prime}, 5^{\prime}$-cyclic AMP by intact and broken cells. J Clin Invest 1983;72:316-324.

-30 Linglart A, Carel JC, Garabedian M, Le T, Mallet E, Kottler ML: GNAS1 lesions in pseudohypoparathyroidism Ia and Ic: genotype phenotype relationship and evidence of the maternal transmission of the hormonal resistance. J Clin Endocrinol Metab 2002;87:189-197.

- 31 Thiele S, de Sanctis L, Werner R, Grötzinger J, Aydin C, Jüppner H, Bastepe M, Hiort O: Functional characterization of GNAS mutations found in patients with pseudohypoparathyroidism type Ic defines a new subgroup of pseudohypoparathyroidism affecting selectively Gsa-receptor interaction. Hum Mutat 2011;32:653-660.

- 32 Iiri T, Herzmark P, Nakamoto JM, van Dop C, Bourne HR: Rapid GDP release from Gs alpha in patients with gain and loss of endocrine function. Nature 1994;371:164-168.

- 33 Makita N, Sato J, Rondard P, Fukamachi H, Yuasa Y, Aldred MA, Hashimoto M, Fujita T, Iiri T: Human G(salpha) mutant causes pseudohypoparathyroidism type Ia/neonatal diarrhea, a potential cell-specific role of the palmitoylation cycle. Proc Natl Acad Sci USA 2007;104:17424-17429.

- 34 Tsai KS, Chang CC, Wu DJ, Huang TS, Tsai IH, Chen FW: Deficient erythrocyte membrane Gs alpha activity and resistance to trophic hormones of multiple endocrine organs in two cases of pseudohypoparathyroidism. Taiwan Yi Xue Hui Za Zhi 1989;88:450-455.

- 35 Gelfand IM, Eugster EA, DiMeglio LA: Presentation and clinical progression of pseudohypoparathyroidism with multi-hormone resistance and Albright hereditary osteodystrophy: a case series. J Pediatr 2006;149:877-880.

- 36 Yu D, Yu S, Schuster V, Kruse K, Clericuzio CL, Weinstein LS: Identification of two novel deletion mutations within the Gs alpha gene (GNAS1) in Albright hereditary osteodystrophy. J Clin Endocrinol Metab 1999;84:32543259.

- 37 Zheng H, Radeva G, McCann JA, Hendy GN, Goodyer CG: Gas transcripts are biallelically expressed in the human kidney cortex: implications for pseudohypoparathyroidism type Ib. J Clin Endocrinol Metab 2001;86:46274629.
Albright F, Forbes AP, Henneman PH: Pseudo-pseudohypoparathyroidism. Trans Assoc Am Physicians 1952;65:337-350.

39 Davies AJ, Hughes HE: Imprinting in Albright's hereditary osteodystrophy. J Med Genet 1993;30:101-103.

40 Wilson LC, Oude-Luttikhuis MEM, Clayton PT, Fraser WD, Trembath RC: Parental origin of Gsa gene mutations in Albright's hereditary osteodystrophy. J Med Genet 1994;31: 835-839.

41 Mantovani G, Bondioni S, Locatelli M, Pedroni C, Lania AG, Ferrante E, Filopanti M, BeckPeccoz P, Spada A: Biallelic expression of the Gsalpha gene in human bone and adipose tissue. J Clin Endocrinol Metab 2004;89:63166319.

-42 Bastepe M, Weinstein LS, Ogata N, Kawaguchi H, Jüppner H, Kronenberg HM, Chung UI: Stimulatory G protein directly regulates hypertrophic differentiation of growth plate cartilage in vivo. Proc Natl Acad Sci USA 2004;101:14794-14799.

43 Faull CM, Welbury RR, Paul B, Kendall-Taylor P: Pseudohypoparathyroidism: its phenotypic variability and associated disorders in a large family. Q J Med 1991;78:251-264.

44 Moses AM, Weinstock RS, Levine MA, Breslau NA: Evidence for normal antidiuretic responses to endogenous and exogenous arginine vasopressin in patients with guanine nucleotide-binding stimulatory protein-deficient pseudohypoparathyroidism. J Clin Endocrinol Metab 1986;62:221-224.

45 Huso DL, Edie S, Levine MA, Schwindinger W, Wang Y, Jüppner H, Germain-Lee EL: Heterotopic ossifications in a mouse model of Albright hereditary osteodystrophy. PLoS One 2011;6:e21755.

46 Mouallem M, Shaharabany M, Weintrob N, Shalitin S, Nagelberg N, Shapira H, Zadik Z, Farfel Z: Cognitive impairment is prevalent in pseudohypoparathyroidism type Ia, but not in pseudopseudohypoparathyroidism: possible cerebral imprinting of Gsalpha. Clin Endocrinol (Oxf) 2008;68:233-239.

47 Long DN, McGuire S, Levine MA, Weinstein LS, Germain-Lee EL: Body mass index differences in pseudohypoparathyroidism type 1a versus pseudopseudohypoparathyroidism may implicate paternal imprinting of Galpha(s) in the development of human obesity. J Clin Endocrinol Metab 2007;92:1073-1079.

48 Kaplan FS, Craver R, MacEwen GD, Gannon FH, Finkel G, Hahn G, Tabas J, Gardner RJ, Zasloff MA: Progressive osseous heteroplasia: a distinct developmental disorder of heterotopic ossification - two new case reports and follow-up of three previously reported cases. J Bone Joint Surg Am 1994;76:425436.

49 Shore EM, Ahn J, Jan de Beur S, Li M, Xu M, Gardner RJ, Zasloff MA, Whyte MP, Levine MA, Kaplan FS: Paternally inherited inactivating mutations of the GNAS1 gene in progressive osseous heteroplasia. N Engl J Med 2002;346:99-106.
50 Ahmed SF, Barr DG, Bonthron DT: GNAS1 mutations and progressive osseous heteroplasia. N Engl J Med 2002;346:1669-1671.

51 Adegbite NS, Xu M, Kaplan FS, Shore EM, Pignolo RJ: Diagnostic and mutational spectrum of progressive osseous heteroplasia $(\mathrm{POH})$ and other forms of GNAS-based heterotopic ossification. Am J Med Genet A 2008;146A:1788-1796.

52 Germain-Lee EL, Schwindinger W, Crane JL, Zewdu R, Zweifel LS, Wand G, Huso DL, Saji M, Ringel MD, Levine MA: A mouse model of Albright hereditary osteodystrophy generated by targeted disruption of exon 1 of the Gnas gene. Endocrinology 2005; 146:46974709.

53 Chen M, Gavrilova O, Liu J, Xie T, Deng C, Nguyen AT, Nackers LM, Lorenzo J, Shen L, Weinstein LS: Alternative Gnas gene products have opposite effects on glucose and lipid metabolism. Proc Natl Acad Sci USA 2005; 102:7386-7391.

54 Liu Z, Segawa H, Aydin C, Reyes M, Erben RG, Weinstein LS, Chen M, Marshansky V, Frohlich LF, Bastepe M: Transgenic overexpression of the extra-large Gsa variant XLas enhances Gsa-mediated responses in the mouse renal proximal tubule in vivo. Endocrinology 2011;152:1222-1233.

55 Yu S, Gavrilova O, Chen H, Lee R, Liu J, Pacak K, Parlow AF, Quon MJ, Reitman ML, Weinstein LS: Paternal versus maternal transmission of a stimulatory G-protein alpha subunit knockout produces opposite effects on energy metabolism. J Clin Invest 2000;105:615-623.

56 Plagge A, Gordon E, Dean W, Boiani R, Cinti S, Peters J, Kelsey G: The imprinted signaling protein XL alpha $s$ is required for postnatal adaptation to feeding. Nat Genet 2004;36: 818-826.

57 Xie T, Plagge A, Gavrilova O, Pack S, Jou W, Lai EW, Frontera M, Kelsey G, Weinstein LS: The alternative stimulatory $\mathrm{G}$ protein alphasubunit XLalphas is a critical regulator of energy and glucose metabolism and sympathetic nerve activity in adult mice. J Biol Chem 2006;281:18989-18999.

58 Skinner JA, Cattanach BM, Peters J: The imprinted oedematous-small mutation on mouse chromosome 2 identifies new roles for Gnas and Gnasxl in development. Genomics 2002;80:373-375.

59 Cattanach BM, Peters J, Ball S, Rasberry C: Two imprinted gene mutations: three phenotypes. Hum Mol Genet 2000;9:2263-2273.

60 Kelly ML, Moir L, Jones L, Whitehill E, Anstee QM, Goldin RD, Hough A, Cheeseman M, Jansson JO, Peters J, Cox RD: A missense mutation in the non-neural G-protein alpha-subunit isoforms modulates susceptibility to obesity. Int J Obes (Lond) 2009;33: 507-518.

61 Cheeseman MT, Vowell K, Hough TA, Jones L, Pathak P, Tyrer HE, Kelly M, Cox R, Warren MV, Peters J: A mouse model for osseous heteroplasia. PLoS One 2012;7:e51835. 
-62 Sakamoto A, Weinstein LS, Plagge A, Eckhaus M, Kelsey G: GNAS haploinsufficiency leads to subcutaneous tumor formation with collagen and elastin deposition and calcification. Endocr Res 2009;34:1-9.

63 de Nanclares GP, Fernández-Rebollo E, Santin I, García-Cuartero B, Gaztambide S, Menéndez E, Morales MJ, Pombo M, Bilbao JR, Barros F, Zazo N, Ahrens W, Jüppner H, Hiort O, Castaño L, Bastepe M: Epigenetic defects of GNAS in patients with pseudohypoparathyroidism and mild features of Albright's hereditary osteodystrophy. J Clin Endocrinol Metab 2007;92:2370-2373.

64 Mariot V, Maupetit-Mehouas S, Sinding C, Kottler ML, Linglart A: A maternal epimutation of GNAS leads to Albright osteodystrophy and parathyroid hormone resistance. J Clin Endocrinol Metab 2008;93:661-665.

-65 Unluturk U, Harmanci A, Babaoglu M, Yasar U, Varli K, Bastepe M, Bayraktar M: Molecular diagnosis and clinical characterization of pseudohypoparathyroidism type-Ib in a patient with mild Albright's hereditary osteodystrophy-like features, epileptic seizures, and defective renal handling of uric acid. Am J Med Sci 2008;336:84-90.

-66 Mantovani G, de Sanctis L, Barbieri AM, Elli FM, Bollati V, Vaira V, Labarile P, Bondioni S, Peverelli E, Lania AG, Beck-Peccoz P, Spada A: Pseudohypoparathyroidism and GNAS epigenetic defects: clinical evaluation of Albright hereditary osteodystrophy and molecular analysis in 40 patients. J Clin Endocrinol Metab 2010;95:651-658.

-67 Jüppner H, Schipani E, Bastepe M, Cole DEC, Lawson ML, Mannstadt M, Hendy GN, Plotkin H, Koshiyama H, Koh T, Crawford JD, Olsen BR, Vikkula M: The gene responsible for pseudohypoparathyroidism type Ib is paternally imprinted and maps in four unrelated kindreds to chromosome 20q13.3. Proc Natl Acad Sci USA 1998;95:11798-11803.

68 Bastepe M, Pincus JE, Sugimoto T, Tojo K, Kanatani M, Azuma Y, Kruse K, Rosenbloom AL, Koshiyama H, Jüppner H: Positional dissociation between the genetic mutation responsible for pseudohypoparathyroidism type $\mathrm{Ib}$ and the associated methylation defect at exon A/B: evidence for a long-range regulatory element within the imprinted GNAS1 locus. Hum Mol Genet 2001;10:1231-1241.

-69 Liu J, Litman D, Rosenberg MJ, Yu S, Biesecker LG, Weinstein LS: A GNAS1 imprinting defect in pseudohypoparathyroidism type IB. J Clin Invest 2000;106:1167-1174.

-70 Bastepe M, Lane AH, Jüppner H: Paternal uniparental isodisomy of chromosome $20 \mathrm{q}$ - and the resulting changes in GNAS1 methylation as a plausible cause of pseudohypoparathyroidism. Am J Hum Genet 2001;68:1283-1289.

-71 Bastepe M, Altug-Teber O, Agarwal C, Oberfield SE, Bonin M, Jüppner H: Paternal uniparental isodisomy of the entire chromosome 20 as a molecular cause of pseudohypoparathyroidism type Ib (PHP-Ib). Bone 2011;48:659662.
72 Fernández-Rebollo E, Lecumberri B, Garin I, Arroyo J, Bernal-Chico A, Goñi F, Orduña R, Spanish PHP Group, Castaño L, de Nanclares GP: New mechanisms involved in paternal $20 \mathrm{q}$ disomy associated with pseudohypoparathyroidism. Eur J Endocrinol 2010;163:953962.

73 Dixit A, Chandler KE, Lever M, Poole RL, Bullman H, Mughal MZ, Steggall M, Suri M: Pseudohypoparathyroidism type $1 \mathrm{~b}$ due to paternal uniparental disomy of chromosome 20q. J Clin Endocrinol Metab 2013;98:E103E108.

74 Lecumberri B, Fernández-Rebollo E, Sentchordi L, Saavedra P, Bernal-Chico A, Pallardo LF, Bustos JM, Castaño L, de Santiago M, Hiort O, Pérez de Nanclares G, Bastepe M: Coexistence of two different pseudohypoparathyroidism subtypes ( $\mathrm{Ia}$ and $\mathrm{Ib}$ ) in the same kindred with independent Gsa coding mutations and GNAS imprinting defects. J Med Genet 2010;47:276-280.

75 Bastepe M, Fröhlich LF, Hendy GN, Indridason OS, Josse RG, Koshiyama H, Körkkö J, Nakamoto JM, Rosenbloom AL, Slyper AH, Sugimoto T, Tsatsoulis A, Crawford JD, Jüppner H: Autosomal dominant pseudohypoparathyroidism type Ib is associated with a heterozygous microdeletion that likely disrupts a putative imprinting control element of GNAS. J Clin Invest 2003;112: 1255-1263.

-76 Linglart A, Gensure RC, Olney RC, Jüppner $\mathrm{H}$, Bastepe M: A novel STX16 deletion in autosomal dominant pseudohypoparathyroidism type Ib redefines the boundaries of a cisacting imprinting control element of GNAS. Am J Hum Genet 2005;76:804-814.

77 Richard N, Abeguilé G, Coudray N, Mittre H, Gruchy N, Andrieux J, Cathebras P, Kottler ML: A new deletion ablating NESP55 causes loss of maternal imprint of A/B GNAS and autosomal dominant pseudohypoparathyroidism type Ib. J Clin Endocrinol Metab 2012;97:E863-E867.

78 Simonsen A, Bremnes B, Ronning E, Aasland R, Stenmark H: Syntaxin-16, a putative Golgi t-SNARE. Eur J Cell Biol 1998;75:223-231.

79 Tang BL, Low DY, Lee SS, Tan AE, Hong W: Molecular cloning and localization of human syntaxin 16 , a member of the syntaxin family of SNARE proteins. Biochem Biophys Res Commun 1998;242:673-679.

80 Fröhlich LF, Bastepe M, Ozturk D, Abu-Zahra $\mathrm{H}$, Jüppner $\mathrm{H}$ : Lack of Gnas epigenetic changes and pseudohypoparathyroidism type Ib in mice with targeted disruption of syntaxin-16. Endocrinology 2007;148:29252935.

-81 Bastepe M, Fröhlich LF, Linglart A, Abu-Zahra HS, Tojo K, Ward LM, Jüppner H: Deletion of the NESP55 differentially methylated region causes loss of maternal GNAS imprints and pseudohypoparathyroidism type Ib. Nat Genet 2005;37:25-27.

82 Chillambhi S, Turan S, Hwang DY, Chen HC, Jüppner H, Bastepe M: Deletion of the noncoding GNAS antisense transcript causes pseudohypoparathyroidism type Ib and biparental defects of GNAS methylation in cis. J Clin Endocrinol Metab 2010;95:39934002.

83 Fröhlich LF, Mrakovcic M, Steinborn R, Chung UI, Bastepe M, Jüppner H: Targeted deletion of the Nesp55 DMR defines another Gnas imprinting control region and provides a mouse model of autosomal dominant PHPIb. Proc Natl Acad Sci USA 2010;107:92759280.

84 Fernández-Rebollo E, Maeda A, Reyes M, Turan S, Fröhlich LF, Plagge A, Kelsey G, Jüppner H, Bastepe M: Loss of XLas (extralarge $\alpha$ ) imprinting results in early postnatal hypoglycemia and lethality in a mouse model of pseudohypoparathyroidism Ib. Proc Natl Acad Sci USA 2012;109:6638-6643.

85 Liu J, Nealon JG, Weinstein LS: Distinct patterns of abnormal GNAS imprinting in familial and sporadic pseudohypoparathyroidism type IB. Hum Mol Genet 2005; 14:95102 .

86 Fernández-Rebollo E, Pérez de Nanclares G, Lecumberri B, Turan S, Anda E, Pérez-Nanclares G, Feig D, Nik-Zainal S, Bastepe M, Jüppner H: Exclusion of the GNAS locus in PHP-Ib patients with broad GNAS methylation changes: evidence for an autosomal recessive form of PHP-Ib? J Bone Miner Res 2011;26:1854-1863.

87 Bliek J, Verde G, Callaway J, Maas SM, De Crescenzo A, Sparago A, Cerrato F, Russo S, Ferraiuolo S, Rinaldi MM, Fischetto R, Lalatta F, Giordano L, Ferrari P, Cubellis MV, Larizza L, Temple IK, Mannens MM, Mackay DJ, Riccio A: Hypomethylation at multiple maternally methylated imprinted regions including PLAGL1 and GNAS loci in BeckwithWiedemann syndrome. Eur J Hum Genet 2009;17:611-619.

88 Mackay DJ, Callaway JL, Marks SM, White HE, Acerini CL, Boonen SE, Dayanikli P, Firth HV, Goodship JA, Haemers AP, Hahnemann JM, Kordonouri O, Masoud AF, Oestergaard E, Storr J, Ellard S, Hattersley AT, Robinson DO, Temple IK: Hypomethylation of multiple imprinted loci in individuals with transient neonatal diabetes is associated with mutations in ZFP57. Nat Genet 2008;40:949951.

89 Perez-Nanclares G, Romanelli V, Mayo S, Garin I, Zazo C, Fernandez-Rebollo E, Martínez F, Lapunzina P, de Nanclares GP, Spanish PHP Group: Detection of hypomethylation syndrome among patients with epigenetic alterations at the GNAS locus. J Clin Endocrinol Metab 2012;97:E1060-E1067.

90 Lefebvre L, Viville S, Barton SC, Ishino F, Keverne EB, Surani MA: Abnormal maternal behaviour and growth retardation associated with loss of the imprinted gene Mest. Nat Genet 1998;20:163-169.

91 Ivanova E, Kelsey G: Imprinted genes and hypothalamic function. J Mol Endocrinol 2011; 47:R67-R74. 
-92 Pasolli HA, Huttner WB: Expression of the extra-large $G$ protein alpha-subunit XLalphas in neuroepithelial cells and young neurons during development of the rat nervous system. Neurosci Lett 2001;301:119-122.

-93 Krechowec SO, Burton KL, Newlaczyl AU, Nunn N, Vlatković N, Plagge A: Postnatal changes in the expression pattern of the imprinted signalling protein XLas underlie the changing phenotype of deficient mice. PLoS One 2012;7:e29753.

94 Klemke M, Pasolli HA, Kehlenbach RH, Offermanns S, Schultz G, Huttner WB: Characterization of the extra-large $\mathrm{G}$ protein alphasubunit XLalphas. 2. Signal transduction properties. J Biol Chem 2000;275:3363333640.

-95 Bastepe M, Gunes Y, Perez-Villamil B, Hunzelman J, Weinstein LS, Jüppner H: Receptormediated adenylyl cyclase activation through XLalpha(s), the extra-large variant of the stimulatory $\mathrm{G}$ protein alpha-subunit. Mol Endocrinol 2002;16:1912-1919.

-96 Linglart A, Mahon MJ, Kerachian MA, Berlach DM, Hendy GN, Jüppner H, Bastepe M: Coding GNAS mutations leading to hormone resistance impair in vitro agonist- and cholera toxin-induced adenosine cyclic $3^{\prime}, 5^{\prime}$-monophosphate formation mediated by human XLas. Endocrinology 2006;147:2253-2262.

\97 Liu Z, Turan S, Wehbi VL, Vilardaga JP, Bastepe M: Extra-long Gas variant XLas protein escapes activation-induced subcellular redistribution and is able to provide sustained signaling. J Biol Chem 2011;286:3855838569.

-98 Izzi B, Francois I, Labarque V, Thys C, Wittevrongel C, Devriendt K, Legius E, Van den Bruel A, D'Hooghe M, Lambrechts D, de Zegher F, Van Geet C, Freson K: Methylation defect in imprinted genes detected in patients with an Albright's hereditary osteodystrophy like phenotype and platelet Gs hypofunction. PLoS One 2012; 7:e38579.
99 Geneviève D, Sanlaville D, Faivre L, Kottler ML, Jambou M, Gosset P, Boustani-Samara D, Pinto G, Ozilou C, Abeguilé G, Munnich A, Romana S, Raoul O, Cormier-Daire V, Vekemans M: Paternal deletion of the GNAS imprinted locus (including Gnasxl) in two girls presenting with severe pre- and postnatal growth retardation and intractable feeding difficulties. Eur J Hum Genet 2005;13: 1033-1039.

100 Aldred MA, Aftimos S, Hall C, Waters KS, Thakker RV, Trembath RC, Brueton L: Constitutional deletion of chromosome $20 \mathrm{q}$ in two patients affected with Albright hereditary osteodystrophy. Am J Med Genet 2002; 113:167-172.

101 Lebrun M, Richard N, Abeguilé G, David A, Coëslier Dieux A, Journel H, Lacombe D, Pinto G, Odent S, Salles JP, Taieb A, Gandon-Laloum S, Kottler ML: Progressive osseous heteroplasia: a model for the imprinting effects of GNAS inactivating mutations in humans. J Clin Endocrinol Metab 2010; 95:3028-3038.

102 Richard N, Molin A, Coudray N, RaultGuillaume P, Jüppner H, Kottler ML: Paternal GNAS mutations lead to severe intrauterine growth retardation (IUGR) and provide evidence for a role of XLas in fetal development. J Clin Endocrinol Metab 2013; 98:E1549-E1556

103 Eaton SA, Williamson CM, Ball ST, Beechey CV, Moir L, Edwards J, Teboul L, Maconochie M, Peters J: New mutations at the imprinted Gnas cluster show gene dosage effects of Gsa in postnatal growth and implicate XLas in bone and fat metabolism but not in suckling. Mol Cell Biol 2012;32:10171029.
04 Liu J, Chen M, Deng C, Bourc'his D, Nealon JG, Erlichman B, Bestor TH, Weinstein LS: Identification of the control region for tissue-specific imprinting of the stimulatory G protein $\alpha$-subunit. Proc Natl Acad Sci USA 2005;102:5513-5518.

105 Puzhko S, Goodyer C, Kerachian M, Canaff L, Misra M, Jüppner H, Bastepe M, Hendy G: Parathyroid hormone signaling via Gas is selectively inhibited by an $\mathrm{NH} 2$-terminally truncated Gas: implications for pseudohypoparathyroidism. J Bone Miner Res 2011 26:2473-2485.

106 Linglart A, Bastepe M, Jüppner H: Similar clinical and laboratory findings in patients with symptomatic autosomal dominant and sporadic pseudohypoparathyroidism type Ib despite different epigenetic changes at the GNAS locus. Clin Endocrinol (Oxf) 2007;67: 822-831.

107 Plagge A, Isles AR, Gordon E, Humby T, Dean W, Gritsch S, Fischer-Colbrie R, Wilkinson LS, Kelsey G: Imprinted Nesp55 influences behavioral reactivity to novel environments. Mol Cell Biol 2005;25:30193026.

108 Chotalia M, Smallwood SA, Ruf N, Dawson C, Lucifero D, Frontera M, James K, Dean W, Kelsey G: Transcription is required for establishment of germline methylation marks at imprinted genes. Genes Dev 2009; 23:105-117.

109 Williamson CM, Turner MD, Ball ST, Nottingham WT, Glenister P, Fray M, Tymowska-Lalanne Z, Plagge A, Powles-Glover N, Kelsey G, Maconochie M, Peters J: Identification of an imprinting control region affecting the expression of all transcripts in the Gnas cluster. Nat Genet 2006;38:350-355.

110 Williamson CM, Ball ST, Dawson C, Mehta S, Beechey CV, Fray M, Teboul L, Dear TN, Kelsey G, Peters J: Uncoupling antisensemediated silencing and DNA methylation in the imprinted Gnas cluster. PLoS Genet 2011;7:e1001347. 